(C) 1982. The Genetical Society of Great Britain

\title{
ANALYSIS OF COMPETITIVE ABILITY AMONG GENOTYPES OF PERENNIAL RYEGRASS
}

\author{
K. MATHER*, J. HILL $†$, and P. D. S. CALIGARI \\ * Department of Genetics, University of Birmingham, Birmingham B15 2TT; $†$ Welsh \\ Plant Breeding Station, Aberystwyth, SY23 3EB; $¥$ Scottish Crop Research Institute \\ (Pentlandfield), Roslin, EH25 9RF, U.K.
}

Received 14.xii.81

\begin{abstract}
SUMMARY
Results are reported from the first year of a competition experiment with three genotypes $(\mathrm{B}, \mathrm{C}$ and $\mathrm{E})$ of perennial ryegrass. The experiment, which was carried out in duplicate, utilised replacement series, i.e., it was of the substitution type. The mean yield in grams of dry matter per plant was measured under two cutting regimes, frequent $(F)$ and infrequent $(R)$. The results could not be fitted adequately by linear regression of the mean yield $(y)$ on the number of plants omitted or substituted $(x)$. Curvilinear regression lines of the form $y=a+b x^{2}$ or $y=a+b_{1} x+b_{2} x^{2}$ were successful in fitting the data, but they led to unacceptable predictions when they were extended from substitution experiments, where $x$ is negative, to addition experiments in which $x$ is positive.

When a square root transformation was used, linear regressions showed an adequate fit with the observations. Furthermore the heterogeneity of the duplicate error variance, found when $y$ itself was employed, was greatly reduced, and the mean square deviations of the observations from the regression lines were homogeneous within the two cutting regimes. The square root transformation also avoids the grossly unacceptable features of polynomial regressions when they are extended to predict the outcome of addition experiments.

The regression coefficients were used to derive estimates of the competitive abilities of the three genotypes in both monocultures (intra-genotypic competition) and duocultures (inter-genotype competition). These competitive values differ between the two cutting regimes, being lower under the $F$ regime than under the $\mathbf{R}$.
\end{abstract}

\section{INTRODUCTION}

THE measurement and comparison of competitive interactions between individuals of like and different genotypes in Drosophila melanogaster were discussed and illustrated by Mather and Caligari (1981) in terms of characters which showed a linear relation between their expressions and the densities of the cultures in which the individuals under observation were raised. Though such a linear regression of expression on density is not essential to their approach, it greatly facilitates the analysis. Indeed the characters that they used were defined and the densities of the cultures they raised were adjusted to achieve it.

In other circumstances, however, notably where the work has an applied aim, the characters to be followed and the densities to be used may be determined, at least in part, by wider considerations. It may therefore be necessary to consider curvilinear relations. An example is afforded by a competition experiment in progress at the Welsh Plant Breeding Station concerning the competitive interactions of three clones of the forage grass Lolium perenne (perennial ryegrass). The analysis of the first year's results from this experiment is the subject of the present discussion. 


\section{THE EXPERIMENT}

From five perennial ryegrass genotypes (clones) used in a previous experiment (Hill and Shimamoto, 1973), three (B, C and E) were chosen for this investigation. Marked morphological differences exist between these three genotypes in that B is short-leaved, densely tillering and with a very prostrate growth habit, whereas both $\mathrm{C}$ and $\mathrm{E}$ have larger leaves, are less densely tillering and have erect growth habits. Furthermore genotype B was collected from an indigenous population in South Wales whilst C and E were derived from the bred cultivars S.24 and S.23 respectively.

Essentially a substitution design was used for the experiment, which, for convenience, may be split into two parts; a series of monocultures and a series of binary mixtures or duocultures. The basic design in terms of plant numbers is illustrated below with reference to genotypes B and C, though obviously the same numbers apply to the $\mathrm{B} / \mathrm{E}$ and $\mathrm{C} / \mathrm{E}$ combinations also used in this experiment.

$\begin{array}{lccccc}\text { B monoculture: } & 20 & 15 & 10 & 5 & \\ \text { B/C duoculture: } & & 15 / 5 & 10 / 10 & 5 / 15 & \\ \text { C monoculture: } & & 5 & 10 & 15 & 20\end{array}$

The experiment was established in a glasshouse with uniform tillers from the three genotypes. These were planted in boxes containing a standard John Innes number 3 compost and surrounded by appropriate guard plants. The experimental plants were allocated at random to the 20 potential positions within a box (see Hill and Shimamoto, loc. cit.). Plants were grown $5 \mathrm{~cm}$ apart in both directions, a density chosen to simulate sward conditions if all the available positions are occupied.

For this experiment a randomised complete block design, with two replicates, was used. Within each replicate all monocultures and duocultures were represented by two boxes, one of which was assigned at random to a frequent $(F)$ cutting regime (cut every three weeks during the growing season), while the other was harvested infrequently (R) (every six weeks during the growing season). There were therefore a total of 24 monocultures and 18 duocultures per replicate, giving 84 boxes in all. At each cut, plants were harvested individually and their dry weights recorded. After every infrequent cut all boxes received an application of complete fertiliser equivalent to 300 kilograms/hectare/annum of nitrogen and $150 \mathrm{kh}^{-1} \mathrm{a}^{-1}$ each of phosphorus and potassium.

The reference density, $N$, is 20 plants per box in all cases, with $x$ plants omitted from the monocultures or substituted by a second genotype in the duocultures. Thus $x$ takes the values $-5,-10$ and -15 . In the duocultures either of the two genotypes can be treated as the primary, or indicator, genotype according to with which of the two corresponding monocultures it is to be compared for the expression of a character. The other genotype is then, of course, the second, or associate, genotype. The expression of the character, $y$, can thus be compared over a series of densities in three relations, by itself in monoculture and in the face of competition from each of the other two genotypes in relevant duocultures. To use Mather and Caligari's notation, the three relations for $\mathrm{B}$ are $\mathrm{B} /-$ in the monoculture 
series, and $\mathrm{B} / \mathrm{C}$ and $\mathrm{B} / \mathrm{E}$ in the two duocultures series. Furthermore, each of the tripartite comparisons can be made under each of the two cutting regimes, $(F)$ and $(R)$.

The results of the year's cutting are given in table 1 . These are set out in each cell of the table not as the yields from the two duplicate boxes, but as the mean together with half the difference between them. To take the monoculture of $\mathrm{B}$ where $x=-5$ as an example the duplicate boxes under frequent cutting gave yields per plant of 0.35 and 0.66 , so giving a mean of 0.505 and a half difference of -0.155 , the negative sign indicating that the yield in duplicate II of the experiment exceeds that in duplicate I.

\section{TABLE 1}

Mean yields per plant (y) in relation to composition of culture, density of indicator genotype (I) and ralue of $x$. The figures in roman are the means of the two replicates and those in italics are the half lifferences. The upper figures in each cell of the table are from the frequent $(F)$ and the lower from the infrequent $(R)$ cutting regime

\begin{tabular}{|c|c|c|c|c|c|c|c|}
\hline \multirow{3}{*}{$\begin{array}{l}I \\
5\end{array}$} & \multirow{3}{*}{$\begin{array}{c}x \\
-15\end{array}$} & \multicolumn{2}{|c|}{ Monocultures } & \multicolumn{4}{|c|}{ Duocultures (indicator/associate) } \\
\hline & & \multicolumn{2}{|c|}{$\mathrm{B} /-$} & \multicolumn{2}{|c|}{$\mathrm{B} / \mathrm{C}$} & \multicolumn{2}{|c|}{$\mathrm{B} / \mathrm{E}$} \\
\hline & & $\begin{array}{l}0.440 \\
1.195\end{array}$ & $\begin{array}{l}-0.210 \\
-0.935\end{array}$ & $\begin{array}{l}0.145 \\
0.005\end{array}$ & $\begin{array}{l}-0.035 \\
-0.035\end{array}$ & $\begin{array}{l}0.160 \\
0.105\end{array}$ & $\begin{array}{l}-0.070 \\
-0.075\end{array}$ \\
\hline 10 & -10 & $\begin{array}{l}0.630 \\
0.720\end{array}$ & $\begin{array}{r}-0.110 \\
0.020\end{array}$ & $\begin{array}{l}0.155 \\
0.065\end{array}$ & $\begin{array}{l}-0.015 \\
-0.005\end{array}$ & $\begin{array}{l}0.185 \\
0.090\end{array}$ & $\begin{array}{l}-0.035 \\
-0.060\end{array}$ \\
\hline 15 & -5 & $\begin{array}{l}0.505 \\
0.595\end{array}$ & $\begin{array}{r}-0.155 \\
0.025\end{array}$ & $\begin{array}{l}0.120 \\
0.210\end{array}$ & $\begin{array}{l}-0.010 \\
-0.140\end{array}$ & $\begin{array}{l}0.185 \\
0.165\end{array}$ & $\begin{array}{l}-0.025 \\
-0.045\end{array}$ \\
\hline 20 & 0 & $\begin{array}{l}0.495 \\
0.645\end{array}$ & $\begin{array}{l}-0.165 \\
-0.115\end{array}$ & & & & \\
\hline I & $x$ & \multicolumn{2}{|c|}{$\mathrm{C} /-$} & \multicolumn{2}{|c|}{$\mathrm{C} / \mathrm{B}$} & \multicolumn{2}{|c|}{$C / E$} \\
\hline 5 & -15 & $\begin{array}{r}4 \cdot 250 \\
10 \cdot 595\end{array}$ & $\begin{array}{r}-0.280 \\
1.095\end{array}$ & $\begin{array}{l}4 \cdot 430 \\
6 \cdot 595\end{array}$ & $\begin{array}{r}-0.510 \\
1.185\end{array}$ & $\begin{array}{l}1 \cdot 645 \\
3 \cdot 015\end{array}$ & $\begin{array}{r}0.255 \\
-1.015\end{array}$ \\
\hline 10 & -10 & $\begin{array}{l}2.730 \\
4.695\end{array}$ & $\begin{array}{r}-0.060 \\
0.535\end{array}$ & $\begin{array}{l}2 \cdot 535 \\
4 \cdot 340\end{array}$ & $\begin{array}{r}-0.485 \\
0.130\end{array}$ & $\begin{array}{l}1.785 \\
1.845\end{array}$ & $\begin{array}{l}-0.305 \\
-0.015\end{array}$ \\
\hline 15 & -5 & $\begin{array}{l}2 \cdot 245 \\
4 \cdot 005\end{array}$ & $\begin{array}{r}-0.105 \\
0.425\end{array}$ & $\begin{array}{l}2 \cdot 170 \\
3 \cdot 820\end{array}$ & $\begin{array}{l}0.450 \\
0.200\end{array}$ & $\begin{array}{l}1 \cdot 285 \\
2 \cdot 805\end{array}$ & $\begin{array}{r}-0.095 \\
0.355\end{array}$ \\
\hline 20 & 0 & $\begin{array}{l}1 \cdot 535 \\
2 \cdot 360\end{array}$ & $\begin{array}{r}-0.125 \\
0.580\end{array}$ & & & & \\
\hline I & $x$ & \multicolumn{2}{|c|}{$\mathrm{E} /-$} & \multicolumn{2}{|c|}{$\mathrm{E} / \mathrm{B}$} & \multicolumn{2}{|c|}{$\mathrm{E} / \mathrm{C}$} \\
\hline 5 & -15 & $\begin{array}{l}3 \cdot 535 \\
7 \cdot 415\end{array}$ & $\begin{array}{l}1.645 \\
0.995\end{array}$ & $\begin{array}{l}2.895 \\
6.455\end{array}$ & $\begin{array}{r}-1 \cdot 185 \\
1.535\end{array}$ & $\begin{array}{l}1 \cdot 535 \\
1 \cdot 200\end{array}$ & $\begin{array}{r}-0.625 \\
0.190\end{array}$ \\
\hline 10 & -10 & $\begin{array}{l}3 \cdot 105 \\
5 \cdot 240\end{array}$ & $\begin{array}{l}0.105 \\
0.860\end{array}$ & $\begin{array}{l}2 \cdot 800 \\
4 \cdot 225\end{array}$ & $\begin{array}{l}0.140 \\
0.585\end{array}$ & $\begin{array}{l}1.475 \\
1.980\end{array}$ & $\begin{array}{l}0.035 \\
0.220\end{array}$ \\
\hline 15 & -5 & $\begin{array}{l}2.225 \\
2.600\end{array}$ & $\begin{array}{l}0.595 \\
0.480\end{array}$ & $\begin{array}{l}2 \cdot 105 \\
2.905\end{array}$ & $\begin{array}{l}0.115 \\
0.205\end{array}$ & $\begin{array}{l}1 \cdot 730 \\
2 \cdot 340\end{array}$ & $\begin{array}{l}0.290 \\
0.290\end{array}$ \\
\hline 20 & 0 & $\begin{array}{l}1.805 \\
2 \cdot 550\end{array}$ & $\begin{array}{l}0.075 \\
0.240\end{array}$ & & & & \\
\hline
\end{tabular}

\section{Polynomial REgRESSIONS}

A simple plot of the data showed that while linear regressions of yield per plant of the indicator genotype on density fitted in some of the cases, it failed to do so in others. Analysis by Mather and Caligari's technique confirmed that this was so. Inspection of the data suggested that a better representation could be obtained by fitting curvilinear regressions which diminished in slope as the reference density was approached. 
The simplest relation of this kind is obtained by regressing $y$ not on $x$ but on $x^{2}$. The estimate of $a$ (the common value of $y$ at $x=0$ ) and the three regression coefficients, $b_{m}$ for the monocultures $(e . g ., \mathrm{B} /-)$ and the two $b_{d} \mathrm{~s}$ for the two series of duocultures $(e . g ., \mathrm{B} / \mathrm{C}$ and $\mathrm{B} / \mathrm{E})$ can be found using the general $\boldsymbol{J}^{-1}$ matrix (Mather and Caligari, table 2). This is repeated in our table 2 but with the necessary corrections made to the signs of

TABLE 2

The general inverted matrix $\mathrm{J}^{-1}$ (corrected from Table 2 of Mather and Caligari, 1981)

$$
\begin{gathered}
{\left[\begin{array}{ccccc}
1 & -r_{m} & -r_{d B} & -r_{d C} & \cdots \\
-r_{m} & r_{m}^{2}+\left(D / S x_{m}^{2}\right) & r_{m} r_{d B} & r_{m} r_{d C} & \cdots \\
-r_{d B} & r_{d B} r_{m} & r_{d B}^{2}+\left(D / S x_{d B}^{2}\right) & r_{d B} r_{d C} & \cdots \\
-r_{d C} & r_{d C} r_{m} & r_{d C} r_{d B} & r_{d C}^{2}+\left(D / S x_{d C}^{2}\right) & \cdots \\
\vdots & \vdots & \vdots & \vdots
\end{array}\right]} \\
\text { all }+D=n-r_{m} S x_{m}-r_{d B} S x_{d B}-r_{d C} S x_{d C} \cdots \\
r_{m}=S x_{m} / S x_{m}^{2} \text { etc. }
\end{gathered}
$$

certain of the elements which were shown incorrectly in the earlier table. (It should be noted, however, that Mather and Caligari's calculations were not invalidated by these errors in their table: the arithmetic matrix which they used is given correctly in their table 4.)

This general matrix is applied to finding the regression of $y$ on $x^{2}$ in each of the six tripartite comparisons by noting that $x$ in the matrix has now become $x^{2}$ and $x^{2}$ has become $x^{4}$, giving $r_{m}=r_{d}=$ $(0+25+100+225) /\left(0+25^{2}+100^{2}+225^{2}\right)=350 / 61250$ and $D=10-$ $3\left(350^{2} / 61250\right)$. While not going into detail for reasons which are made clear later, we note that quadratic regressions give a better fit in 5 of the 6 tripartite sets of data, though with one set (indicator $B$ under the $R$ cutting regime) linear regression is a little better than quadratic.

A further improvement of fit was sought by fitting a polynomial relation of the general form $y=a+b_{1} x+b_{2} x^{2}$. In the present case such polynomials are most conveniently calculated by treating $x$ and $x^{2}$ as two separate variates, $x_{1}$ and $x_{2}$, and carrying out the estimation of $b_{1}$ and $b_{2}$ by the technique of multiple regression.

As would be expected, the use of the polynomial regression, $L+Q$, always gives a better fit to the data, that is a smaller value for $S(O-E)^{2}$, than does linear (L) or quadratic (Q) regression (table 3 ). In some cases

TABLE 3

$\mathrm{S}(\mathrm{O}-\mathrm{E})^{2}$ from the six tripartite sets of observations after fitting linear $(L)$, quadratic $(Q)$ and polynomial $(L+Q)$ regressions

$\begin{array}{ccccc}\begin{array}{c}\text { Cutting } \\ \text { regime }\end{array} & \begin{array}{c}\text { Indicator } \\ \text { genotype }\end{array} & \text { L } & \text { Regression fitted } & \text { Q } \\ & \text { B } & 0.092907 & 0.040487 & \text { L + Q } \\ \text { F } & \text { C } & 0.825185 & 0.103525 & 0.085762 \\ & \text { E } & 0.118907 & 0.111795 & 0.025980 \\ & \text { B } & 0.124489 & 0.180340 & 0.007886 \\ \text { R } & \text { C } & 7.914823 & 3.537666 & 2.668296 \\ & \text { E } & 2.628856 & 0.478994 & 0.467880\end{array}$


the improvement is large but in others it is small or even trivial. In considering the significance of the improvements of fit, however, it must be remembered that when using the $\mathrm{L}+\mathrm{Q}$ regressions $S(O-E)^{2}$ is a sum of squares corresponding to only $3 \mathrm{df}$, since 7 parameters have been fitted to the 10 observations in each tripartite set, whereas when using $\mathrm{L}$ or $\mathrm{Q}$ regressions, the $S(O-E)^{2}$ corresponds to 6 df since only $a, b_{m}, b_{d i}$ and $b_{d j}$ have been estimated from the 10 observations.

Although the $L+Q$, and in the main the $Q$ regressions, give a better fit than do $L$ regressions, they are greatly inferior to it in another respect. The expression of the character declines as the density of the plants in the monocultures increases from $N-15=5$ to $N=20$, the reference density, and we must expect this decline to continue when $x$ becomes positive as the density increases beyond $N$. The linear regression, $y=a+b x$ incorporates this expectation, but neither the quadratic $y=a+b x^{2}$ nor the polynomial $y=a+b_{1} x+b_{2} x^{2}$ does so. With the quadratic there must be a minimum when $2 x=0$, i.e., at $N$, beyond which this relation implies a rising, not a declining expression of the character, or to use other words, a decreasing not an increasing competition as the density increases. With the polynomial regression the minimum value of $y$ is attained when $x=$ $b_{1} / 2 b_{2}$, but again it carries the same unacceptable expectation of increasing: expression and decreasing competition when density increases beyond its value at minimum $y$. Furthermore with the polynomial relation, this minimum may be reached below the reference density, as is illustrated in fig. 1 for monocultures of genotype $C$ under the $R$ cutting regime.

Thus while quadratic and polynomial regressions give better fits with the observed results, they are unacceptable because of their implication of decreasing competition at densities higher than those used in the experiment. A way out might be sought by introducing a cubic term into the polynomial. This, however, would not only increase the weight of calculation required by the analysis and complicate further the comparisons between competitive interactions: it would also demand more elaborate experiments for the derivation and testing of the regressions. In the present case, to add a cubic component to the linear and quadratic would just yield regressions giving perfect fits to the observations and so denying the possibility of directly testing goodness of fit. Doubtless also, new problems would be raised of the unacceptability of the implications of the regression lines. A solution to the problem must be sought in a different way.

\section{Transformation OF $y$}

If $y=b x^{2}, \sqrt{y}=\sqrt{b} x$, and a linear relation of $y$ to $x$ is achieved. $y=a+b_{1} x+b_{2} x^{2}$, which we have found to fit the observations much more adequately than $y=a+b x$, is a more complex relation than $y=b x^{2}$, but it does suggest the use of the square root transformation of $y$ might overcome much of our difficulty. Furthermore use of the relation $\sqrt{y}=a+b x$ would do away with the implied decrease in competition when $x$ became positive as well as going at least a long way towards giving linear regressions which adequately fitted the observations.

The basic data (table 1) were transformed by taking the square roots of the observations from the duplicate boxes separately. The means and half differences of the square roots of the pairs of duplicate observations 


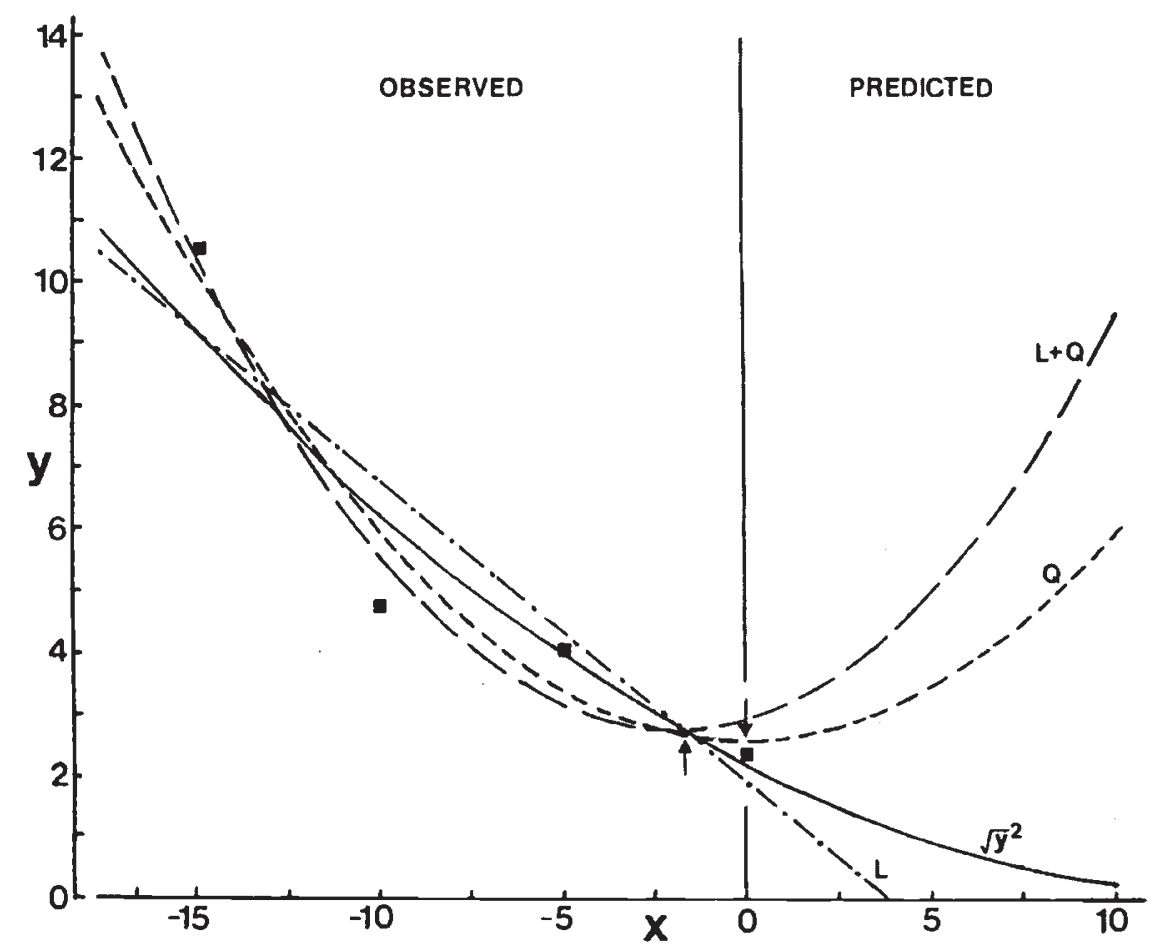

FIG. 1.-Observation and expectations for the monoculture of genotype $\mathbf{C}$ with infrequent cutting. The four observed points are shown by filled squares. The regression of $y$ on $x$ is marked $\mathrm{L}$, that on $x^{2}$ is marked $\mathrm{Q}$ and that on $x$ and $x^{2}$ jointly is marked $\mathrm{L}+\mathrm{Q}$. The solid line marked $\sqrt{y^{2}}$, was obtained from the linear regression of $\sqrt{y}$ on $x$, with the values of $\sqrt{y}$ squared to transform them back to the scale of $y$. Though calculated from the observations ranging from $x=-15$ to $x=0$ the regressions are extended to values of $x$ up to 10 to illustrate the predictions to which they lead when $x$ becomes positive. Though the $Q$ and $L+Q$ fit the observed points well, the predictions to which they lead when $x>0$ are clearly unacceptable. $\sqrt{y^{2}}$ fits the observations better than L, and leads to acceptable predictions. The arrow pointing downwards marks the minimum value of the $Q$ line and that pointing upwards the minimum value of $L+Q$.

were then found, and the calculations of $a, b_{m}, b_{d i}$ and $b_{d i}$ proceed in the ordinary way, using the $J^{-1}$ matrix of table 2 . Since $S x=-30$ and $S x^{2}=350$ are the same for all monocultures and duocultures, all $r=-30 / 350$ and since there are 10 observations in each tripartite set $D=$ $10-\left[3\left(-30^{2} / 350\right)\right]=80 / 35$. The arithmetic matrix is shown in table 4 . The estimates of $a, b_{m}, b_{d i}$ and $b_{d i}$ obtained from each tripartite set are given in table 5.

\section{TABLE 4}

The inverted matrix for linear regressions in the present experiment

$\begin{array}{llll}0.437500000 & 0.037500000 & 0.037500000 & 0.037500000 \\ 0.037500000 & 0.006071429 & 0.003214286 & 0.003214286 \\ 0.037500000 & 0.003214286 & 0.006071429 & 0.003214286 \\ 0.037500000 & 0.003214286 & 0.003214286 & 0.006071429\end{array}$


TABLE 5

Estimates of the parameters using transformed data $(\sqrt{\mathrm{y}})$ as the dependent variate (all entries $\left.\times 10^{3}\right)$

Cutting regime
Indicator
$a$
$b_{m}$
$b_{d i}$
$b_{d i}$
$i$
$j$

B
$595 \cdot 00$
$-9 \cdot 21$
$18 \cdot 86$
$15 \cdot 86$
C
E

$\begin{array}{cc}\text { F } & \\ \text { C } & \text { E } \\ 1172 \cdot 50 & 1351 \cdot 25 \\ -56.29 & -33.82 \\ -55.07 & -23.96 \\ -8.64 & 10.54 \\ \text { B } & \text { B } \\ \text { E } & \text { C }\end{array}$

B
$647 \cdot 19$
$-22 \cdot 03$
$33 \cdot 54$
$29 \cdot 04$
C
E

$\begin{array}{cc}\mathbf{R} & \\ \mathbf{C} & \mathbf{E} \\ 1480 \cdot 00 & 1472 \cdot 50 \\ -102 \cdot 79 & -78 \cdot 21 \\ -70 \cdot 14 & -64 \cdot 86 \\ -9 \cdot 07 & 17 \cdot 57 \\ \text { B } & \text { B } \\ \text { E } & \text { C }\end{array}$

The genotypes corresponding to $i$ and $j$ in the designations of the duoculture regressions are shown at the foot of each column.

The value expected for each observation is found from $Y=a+b x$ using the relevant estimates of $a, b_{m}$ and $b_{d}, x$ taking the value $0,-5,-10$ or -15 as appropriate. The relation of the calculated regression to the observations is illustrated in fig. 2, and overall this fit of observations with expectation appears reasonably good. The goodness of fit is, however, testable statistically by finding $S(O-E)^{2}$ from each tripartite set, dividing by 6 to give the mean square difference between observed and expected values, and comparing this with the duplicate error variance obtained from the variation in the half differences from the duplicate observations. Since there are 10 such half differences from each tripartite set, their mean square variation has $9 \mathrm{df}$. The mean square of $(O-E)$ and the duplicate error variances are shown for each of the six tripartite sets in table 6.

TABLE 6

The mean square deviations from the regression lines $(M S D)$ and the mean square for duplicate error (MSE) in the six tripartite sets of observations (all entries $\times 10^{3}$ )

\begin{tabular}{|c|c|c|c|c|c|c|}
\hline & & $\mathbf{F}$ & & & $\mathbf{R}$ & \\
\hline Indicator & B & C & E & B & C & E \\
\hline $\begin{array}{l}\text { MSD } \\
\text { MSE }\end{array}$ & $\begin{array}{r}11.300 \\
2.464\end{array}$ & $\begin{array}{r}9 \cdot 314 \\
10 \cdot 563\end{array}$ & $\begin{array}{r}2.985 \\
49.856\end{array}$ & $\begin{array}{l}10 \cdot 400 \\
19 \cdot 218\end{array}$ & $\begin{array}{l}45 \cdot 712 \\
22 \cdot 222\end{array}$ & $\begin{array}{r}25.608 \\
5.666\end{array}$ \\
\hline
\end{tabular}

If $S(O-E)^{2}$ is pooled over all six sets and divided by $6 \times 6=36 \mathrm{df}$, the overall mean square turns out to be 0.017553 , while a similar pooling of the duplicate error variances yields a mean square of 0.018331 for $6 \times 9=$ $54 \mathrm{df}$. A fully acceptable fit of the linear regressions to the data is indicated. This close agreement conceals differences in individual estimates. Taken singly, two of the six sets show differences between mean square deviations and duplicate error variance which are significant at the 5 per cent level and one shows a difference significant at the 1 per cent level. At the same time it should be noted that in the difference significant at 1 per cent, shown by indicator $\mathrm{E}$ under the $\mathrm{F}$ cutting regime, the mean square deviation is in fact subnormal by comparison with the error variance, while the set for indicator $E$ under the $R$ regime shows a mean square deviation significantly greater than error at 5 per cent. If the two are pooled the mean square deviation is lower than error variance but not significantly so. 
$F$
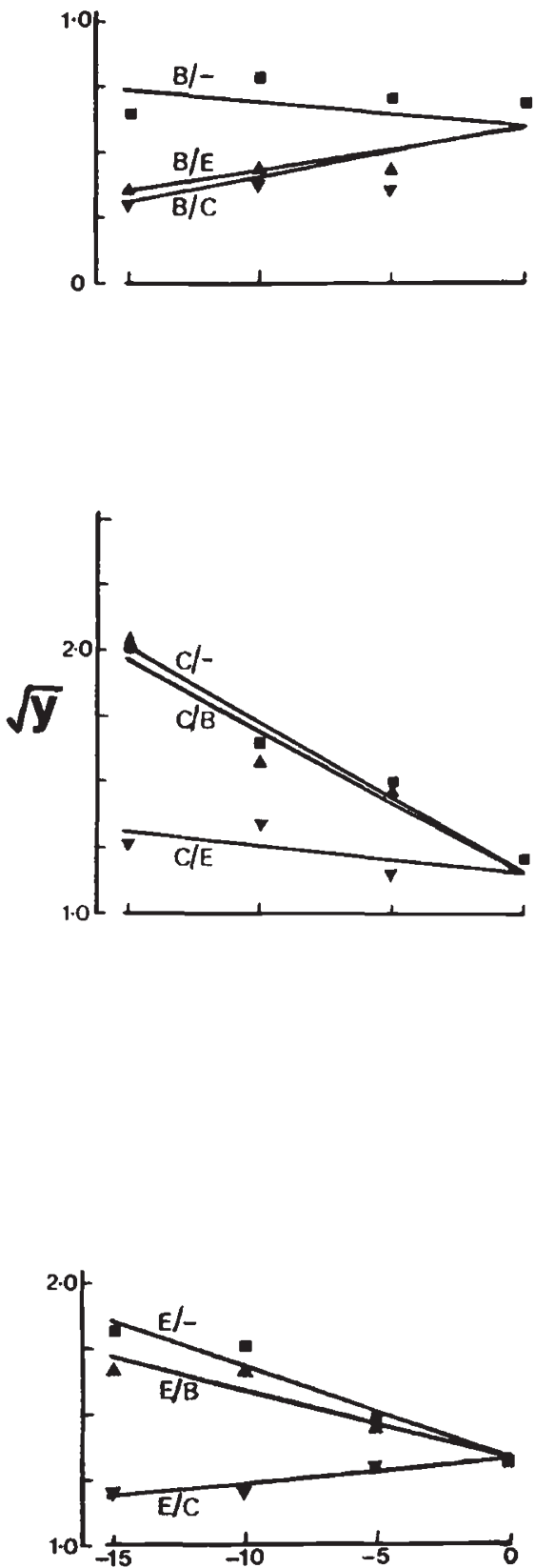

$\mathbf{R}$
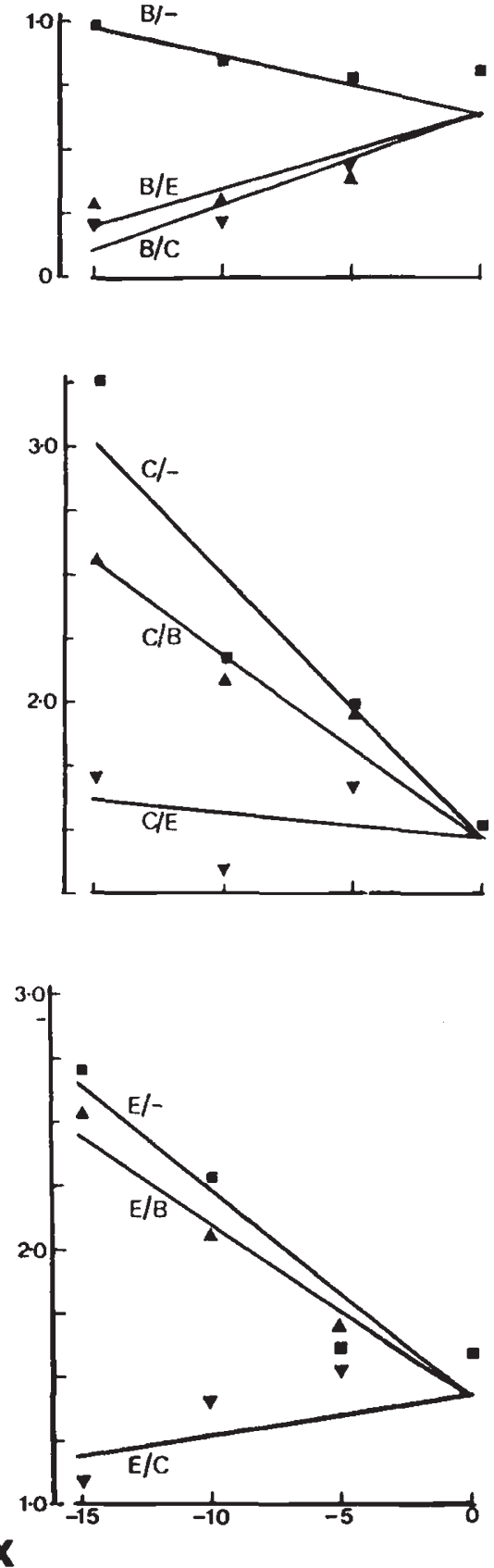

Fig. 2.-The observed points and the linear regressions of $\sqrt{y}$ on $x$ from the six tripartite sets of data stemming from the three genotypes $(B, C$ and $E$ ) as indicators under the two cutting regimes $\mathbf{F}$ and $\mathbf{R}$. The observations from monocultures are shown by squares and those from duocultures by triangles, the upward pointing triangles relating to the upper and the downward triangles to the lower of the two duoculture regressions in each case. 
The problem arises from significant heterogeneity among the six estimates of duplicate error variance, as revealed by Bartlett's test. This heterogeneity stems solely from differences among the estimates from the three tripartite sets under the $\mathrm{F}$ cutting regime. Thus the square root transformation has gone a long way towards removing the heterogeneity among the error variances but has not removed it entirely. No such heterogeneity is found among the mean square deviations from the regression lines for the three sets under the $\mathrm{F}$ regime or for their counterparts under the $R$ regime. There is a significant difference between the overall mean square deviations of the $\mathrm{F}$ and $\mathrm{R}$ data but the difference in cutting regime to which this is related makes it difficult neither to accept nor to understand.

Taken all round, therefore, while the estimates of duplicate error variation still leave something to be desired, there is no compelling indication that the fit of the linear regression model to the data is other than acceptable. At the same time the overall mean square deviation derived from $S(O-E)^{2}$, pooled over indicator genotypes separately for the two cutting regimes, appears to offer a better basis for finding the variances and standard errors of the estimates of the various parameters, and has been used for this purpose. Thus, for example, for the tripartite sets under the $\mathrm{F}$ regime the pooled estimate of the mean square deviation is $V_{F}=$ $0 \cdot 007867$. The variances of $a$ and the three $b$ 's are obtained by multiplying $V$ by the appropriate items on the leading diagonal of table 4 . So the variance of $a$ in the $\mathrm{F}$ sets is $0.437500 V_{F}=0.003442$ and the standard error is 0.058668 . Similarly each $b$ has a variance of $0.006071 V_{F}=$ 0.000047766 and a standard error of 0.006911 . Correspondingly, since the pooled $V$ for the R regime is 0.027239 the variance of $a$ in the three $R$ sets is $0.437500 V_{R}=0.011917$, giving a standard error of 0.109167 , and for each $b$ the variance is 0.000165385 giving 0.012860 as the standard error. The estimates of two different $b$ 's from the same tripartite set have a covariance of 0.003214 , and the variance of their difference is thus $2(0.006071-0.003214) V$ which equals 0.000044956 in the $\mathrm{F}$ series and 0.000155656 in the $R$, the corresponding standard errors being 0.006704 and $0 \cdot 012476$.

\section{INTERPRETATION: THE COMPETITIVE INTERACTIONS}

The value of $a$ tells us that at the reference density of 20 plants per box, the yield per plant of genotype B is significantly lower under both cutting regimes than the yields of $C$ and $E$, which do not differ significantly from one another. The average yield of the three genotypes is lower under the $\mathrm{F}$ regime than under the $\mathrm{R}$, and the difference appears homogeneous over the three genotypes.

The main interest however, lies in the regression coefficients and the information that they can give us about the competitive interactions among the three genotypes in the two cutting regimes. Now as Mather and Caligari (l.c.) point out, the monoculture regression line of slope $b_{m}$ is the line obtained if a plant is assumed to be substituted by its absence and is thus the line that would be obtained if plants of a different genotype having no competitive effect on the indicator were substituted for the individuals of the indicator that have been removed. In this sense $b_{m}$ is the slope 
of the line representing substitution by individuals exerting zero competitive pressure. If on the other hand every plant of the indicator genotype removed was substituted by another of identical genotype, and hence exerting the same competitive pressure, the expression of the character would remain constant within the limits of error variance, and the regression coefficient would be 0 (Mather and Caligari's $b_{0}$ line). Thus the competitive effect of the indicator genotype on itself, that is the magnitude of its intra-genotypic competitive pressure, is measured by $b_{0}-b_{m}=-b_{m}$ which for example in the case of $E$ as indicator under the $R$ regime is $-(-0.078214)=0.078214$. Similarly, to continue with this example, just as $b_{0}$ is the slope expected when further plants of the indicator genotype $E$ are used for the substitution, when plants of B are substituted instead, the inter-genotypic competitive pressure that the $\mathrm{B}$ genotype exerts on $\mathrm{E}$ is measured by $b_{d B}-b_{m}$, that is $-0.064857-(-0.078214)=0.013357$. This is only 17 per cent of the competitive pressure which $E$ exerts itself. When plants of $C$ are substituted for those of $\mathrm{E}$ we find $b_{d C}=0.017571$ and the inter-genotypic pressure of $\mathrm{C}$ on $\mathrm{E}$ becomes $0.017571+0.078214=0.095786$, which is 122 per cent of the intra-genotypic pressure of $\mathrm{E}$.

The regression coefficients of table 5 converted into competitive pressures in this way are set out in table 7 . The competitive pressure is denoted by $c$ with two subscripts the first of which is the indicator genotype and the second the associate.

TABLE 7

Estimates of competitive pressures (c) in all nine combinations of indicator and associate. The leading diagonal shows intra-genotypic competitive pressures in the monocultures. The upper figures in each cell relate to the $F$ and the lower to the $R$ cutting regimes (all entries $\times 10^{3}$ )

\begin{tabular}{ccccc} 
Associate & \multicolumn{4}{c}{ Indicator } \\
B & B & C & E & Mean \\
& $9 \cdot 214$ & 1.214 & $9 \cdot 857$ & 6.762 \\
C & 22.027 & 32.642 & 13.357 & 22.675 \\
& 28.071 & 56.286 & 44.357 & 42.905 \\
E & 55.571 & 102.786 & 95.786 & 84.714 \\
& 25.071 & 47.643 & 33.821 & 35.512 \\
Mean & 51.071 & 93.714 & 78.214 & 74.333 \\
& 20.785 & 35.048 & 29.345 & 28.393 \\
& 42.890 & 76.381 & 62.452 & 60.574
\end{tabular}

The results of an analysis of variance of these data are given in table 8 . The analysis is made first on the sums and then on the differences of the values of $c$ under the two cutting regimes. There are nine sums and nine differences one of each from each cell of table 7. Each of the sums and differences is compounded of two observations and all their sums of squares must thus be divided by 2 to put them on a single observation basis.

The nine sums yield eight df, which can be subdivided into two for differences among indicators (I), two for differences among associates (A) and four for IXA interactions. Each of these can usefully be subdivided as we shall see below. The differences yield nine df, the ninth reflecting the departure of the overall difference from zero and so affording a test of the impact of cutting regime (T) on competition. The remaining eight 
df fall into three groups paralleling those derived from the sums: two df test the interaction $I \times T$, two the interaction $A \times T$, and four the second order interaction $\mathrm{I} \times \mathrm{A} \times \mathrm{T}$.

The error variance in table 8 is derived from the mean square deviation in preference to the duplicate error variation. Further, since all the comparisons used in the analysis of variance draw equally on results from the two cutting regimes, the difference in the mean square deviations between regimes need cause us no concern: the appropriate error variance is derived from the average of two mean square deviations, viz $V=0 \cdot 0175536$. The items in the three cells on the leading diagonal of the table are all of the form $-b_{m}$ and so are subject to an error variance of $0.0060714 \mathrm{~V}=$ 0.0001066 . Those in the six off-diagonal cells, however, are of the form $b_{d i}-b_{m}$ and so are subject to an error variance $0 \cdot 0057143 \mathrm{~V}=0.0001003$. These two error variances are similar and have been combined in the proportion $\frac{1}{3}: \frac{2}{3}$ to give 0.0001024 so reflecting the proportion of diagonal to off-diagonal items.

Since $V$, from which this error variance was derived, was based on $36 \mathrm{df}$ (18 from each cutting regime) each sum of squares in the analysis can be divided by 0.0001024 to give a $\chi^{2}$ by which its significance can be tested. Each $\chi^{2}$ has, of course, the same number of $\mathrm{df}$ as the sum of squares from which it was derived. These $\chi^{2}$ s are shown alongside the mean squares in table 8.

Three comparisons in the analysis are highly significant, $\mathrm{T}$ (the difference in effect of the cutting regimes), I (the differences among the genotypes as indicators), and $\mathrm{A}$ (their differences as associates). The I and A comparisons each involve $2 \mathrm{df}$ and so can be broken down further. The I item has been divided into $I_{1}$ based on the comparison $(C+E-2 B)$, and $I_{2}$ based on $(C-E)$. The $A$ sum of squares is similarly partitioned into $A_{1}$ and $A_{2}$ based on the same two comparisons. $I_{1}$ and $A_{1}$ are both highly significant while neither $I_{2}$ nor $A_{2}$ is formally significant though $I_{2}$ has a probability $<0 \cdot 1$.

TABLE 8

\begin{tabular}{|c|c|c|c|c|}
\hline \multicolumn{5}{|c|}{ Analysis of variance of competitive pressures (c) (all MS $\left.\times 10^{4}\right)$} \\
\hline Item & df & MS & $x^{2}$ & $\mathbf{P}$ \\
\hline $\begin{array}{l}\text { Cutting (T) } \\
\text { Indicators (I) }\end{array}$ & $\begin{array}{l}1 \\
2\end{array}$ & $\begin{array}{r}46 \cdot 604 \\
8.642\end{array}$ & $\begin{array}{l}45 \cdot 51 \\
16 \cdot 88\end{array}$ & $\begin{array}{l}<0.001 \\
<0.001\end{array}$ \\
\hline $\begin{array}{l}I_{1} \\
I_{2}\end{array}$ & $\begin{array}{l}1 \\
1 \\
\end{array}$ & $\begin{array}{r}14 \cdot 393 \\
2 \cdot 890 \\
\end{array}$ & $\begin{array}{r}14 \cdot 06 \\
2 \cdot 82 \\
\end{array}$ & $\begin{array}{c}<0.001 \\
0.1-0.05\end{array}$ \\
\hline Associates (A) & 2 & $41 \cdot 053$ & $80 \cdot 18$ & $<0.001$ \\
\hline $\begin{array}{l}A_{1} \\
A_{2} \\
\end{array}$ & $\begin{array}{l}1 \\
1 \\
\end{array}$ & $\begin{array}{r}79 \cdot 736 \\
2 \cdot 369 \\
\end{array}$ & $\begin{array}{r}77 \cdot 87 \\
2 \cdot 31 \\
\end{array}$ & $\begin{array}{c}<0.001 \\
0 \cdot 2-0.1\end{array}$ \\
\hline $\begin{array}{l}\mathbf{I} \times \mathbf{A} \\
\qquad \begin{array}{l}\mathrm{I}_{1} \times \mathrm{A}_{\mathrm{I}} \\
\text { Rest }\end{array}\end{array}$ & $\begin{array}{l}4 \\
1 \\
3\end{array}$ & $\begin{array}{l}2 \cdot 274 \\
8 \cdot 260 \\
0 \cdot 278 \\
\end{array}$ & $\begin{array}{l}8.88 \\
8.07 \\
0.81 \\
\end{array}$ & $\begin{array}{c}0.1-0.05 \\
0.01-0.001 \\
0.9-0.8\end{array}$ \\
\hline $\begin{array}{l}T \times I_{1} \\
T \times I_{2} \\
T \times A_{1} \\
T \times A_{2} \\
T \times I \times A \\
\text { Error }\end{array}$ & $\begin{array}{r}1 \\
1 \\
1 \\
1 \\
4 \\
36\end{array}$ & $\begin{array}{l}2.285 \\
0.507 \\
5.954 \\
0.067 \\
0.517 \\
1.024\end{array}$ & $\begin{array}{l}2.23 \\
0.50 \\
5 \cdot 81 \\
0.07 \\
2.02\end{array}$ & $\begin{array}{c}0.2-0.1 \\
0.5-0.3 \\
0.02-0.01 \\
0.8-0.7 \\
0.8-0.7\end{array}$ \\
\hline
\end{tabular}

The items in each box show the breakdown of the composite item immediately above. 
So genotype B differs sharply from both $\mathrm{C}$ and $\mathrm{E}$ in its competitive interactions while this analysis fails to reveal any significant difference between $\mathrm{C}$ and $\mathrm{E}$. We will, however, return to this point later.

Of the interaction terms in table $8 \mathrm{I}_{1} \times \mathrm{A}_{1}$ and $\mathrm{T} \times \mathrm{A}_{1}$ are significant, but $T \times I_{1}$ is not. If we pool all the sub-significant items in the analysis, including $I_{2}$ and $A_{2}$ their joint mean square is $0 \cdot 0000918$, so agreeing well with the error variance, $0 \cdot 0001024$.

Table 7 can be regarded as formally like a table of diallel crosses among three inbred lines, and it could be subjected to the analysis of variance appropriate to diallel tables (Hayman, 1954; Durrant, 1965). This analysis uses a set of comparisons differing from those of the customary form which we have employed, and although in the present case the diallel analysis as a whole has no advantage over the more customary form, the types of comparison on which it depends are of help in clarifying two points arising from our results.

In the first place, while our analysis shows B clearly to behave differently from $C$ and $E$, it has given no significant evidence of a difference between $C$ and $E$. Now if we take the results in the four cells of the table that involve only $\mathrm{C}$ and $\mathrm{E}$, the customary partition of the $3 \mathrm{df}$ is into $\left(c_{\mathrm{CC}}+c_{\mathrm{CE}}-\right.$ $\left.c_{\mathrm{EC}}-c_{\mathrm{EE}}\right),\left(c_{\mathrm{CC}}-c_{\mathrm{CE}}+c_{\mathrm{EC}}-c_{\mathrm{EE}}\right)$ and $\left(c_{\mathrm{CC}}-c_{\mathrm{CE}}-c_{\mathrm{EC}}+c_{\mathrm{EE}}\right)$, the first of two which we might denote as $I_{2}^{\prime}$ and $A_{2}^{\prime}$ since they are like $I_{2}$ and $A_{2}$ except that they do not involve any combination of $C$ or $E$ with $B$, while the third is identical with $I_{2} \times A_{2}$. When the sums of squares are evaluated $I_{2}^{\prime}=$ 0.0002910 and $A_{2}^{\prime}=0.0002925$, which on summing give a sum of squares of 0.0005670 for $2 \mathrm{df}, \mathrm{I}_{2} \times \mathrm{A}_{2}$ being 0.0000135 as before. The diallel analysis makes a different partition of the sum of squares using three comparisons two of which are $\left(c_{\mathrm{CC}}-c_{\mathrm{EE}}\right)$ and $\left(c_{\mathrm{CE}}-c_{\mathrm{EC}}\right)$, the third still taking the same form as $I_{2} \times A_{2}$. The sums of squares from the first two comparisons are $\frac{1}{4}(0 \cdot 159072-0 \cdot 112035)^{2}=0 \cdot 0005531$ and $\frac{1}{4}(0 \cdot 141357-$ $0 \cdot 140143)^{2}=0.0000004$, which of course sum to 0.0005535 just as do $I_{2}^{\prime}+A_{2}^{\prime}$. Clearly the second of our two new comparisons is not significant $(P=0.95)$ but the first gives $\chi_{1}^{2}=5.40$ with $P=0.05-0.02$. Thus $C$ and $\mathrm{E}$ do differ in respect of their competitive pressures, $\mathrm{C}$ being a stronger competitor than $\mathrm{E}$, but the second comparison combined with the lack of significance of $I_{2} \times A_{2}$, shows that each exerts the same inter-genotypic pressure on the other as it does intra-genotypically on itself.

The second point arises from the significant interaction $I_{1} \times A_{1}$ revealed by our first analysis. Inspection of the row and column means in table 7 suggests that not only is $\mathrm{B}$ a poorer competitor than $\mathrm{C}$ and $\mathrm{E}$, as the earlier analysis confirms, but that at the same time, it exerts as an associate a different relative pressure on $\mathrm{C}$ and $\mathrm{E}$ as indicators than it suffers as an indicator from the pressures of $\mathrm{C}$ and $\mathrm{E}$ as associates. This is further brought out by two comparisons that we can make similar to the $\left(c_{\mathrm{CE}}-c_{\mathrm{EC}}\right)$ that we have already used. $\left(c_{\mathrm{BC}}-c_{\mathrm{CB}}\right)$ and $\left(c_{\mathrm{BE}}-c_{\mathrm{EB}}\right)$ give sums of squares of 0.0006197 and 0.0007003 respectively, yielding $\chi_{1}^{2}=6.05$ and $\chi_{1}^{2}=6.84$, both with $P \simeq 0.01$. Furthermore, if we pool these, we find $\chi_{2}^{2}=$ 12.89 which can be partitioned in a different way to produce $\chi_{1}^{2}=12 \cdot 88$ testing the joint difference $\left(c_{\mathrm{BC}}-c_{\mathrm{CB}}+c_{\mathrm{BE}}-c_{\mathrm{EB}}\right)$, and $\chi_{1}^{2}=0.012$ testing the heterogeneity of the differences by $\left(c_{\mathrm{BC}}-c_{\mathrm{CB}}-c_{\mathrm{BE}}+c_{\mathrm{EB}}\right)$. The latter is clearly not significant, but $\chi_{1}^{2}$ testing the joint difference has $\mathrm{P}<0 \cdot 001$. 
Thus the response of $\mathrm{B}$ as indicator to the competitive pressures exerted on it by $C$ and $E$ as associates differs from the responses of $C$ and $E$ to the pressure exerted by $B$. Now the response of an indicator to the competitive pressure of an associate will depend not only on the level of pressure the associate exerts, but also on its own capacity for withstanding that pressure. The top row of table 7 , where $B$ is the associate, reflects the ability of the three genotypes to withstand the low level of competitive pressure exerted by $\mathrm{B}$, and taking the two cutting regimes together this appears to be much the same for all the three of them. But if we look at the leftmost column, where $B$ is the indicator, we see that while it has up to a point withstood the pressures exerted by $\mathrm{C}$ and $\mathrm{E}$, it withstands them less well than it does the pressure exerted by itself in monoculture. We are thus led to infer within this single species, $L$. perenne, the same distinction between pressure, or aggressiveness, and resistance, or sensitivity, to competition that Breese and Hill (1973) were led to draw when analysing data from duocultures of weeds (Williams, 1962) and grass species (Norrington-Davies, 1968). In our data these two properties are correlated, as we might indeed expect them commonly to be, but the extent and strength of the correlation requires further analysis and discussion.

\section{ConClusion}

Polynomial regression can give satisfactory fits to the average yields per plant of the three genotypes of $L$. perenne in the mono- and duo-cultures of this substitution experiment. They are, however, unacceptable because they lead to unrealistic predictions if extrapolated to higher densities. They also, of course, do nothing to reduce the heterogeneity of the duplicate error variances observed in different parts of the experiment. This suggests the use of regressions not of $y$ on some function involving powers of $x$, but of a transformed $y$ on $x$ itself, the transformation being such as to yield realistic predictions over any range of densities likely to be brought into use, while at the same time reducing the heterogeneity of the error variances.

Two transformations were considered, the use of $\log y$ and of $\sqrt{y}$. The log transformation has not been discussed because it proved less satisfactory than the square root both in giving linear regressions of good fit and in the reduction of problems with the duplicate error variances. The square root transformation, on the other hand, has led to linear regressions which adequately fit the data and to residual deviations from the regression lines which are homogeneous except between data from the two cutting regimes, where indeed homogeneity would not necessarily be expected. It has also resolved a great deal, though not all, of the heterogeneity among the duplicate error variances and it has led to measurements of competitive interaction that are capable of informative analysis as well as being relatable to differences in habit of growth of the three genotypes.

A different transformation has been employed by Wright (1981) who has adapted the use of the reciprocal of yield per plant, developed by earlier authors for the analysis of density experiments with monocultures, for the analysis of duocultures also. He uses the relation $w_{a}^{-1}=$ $A+B_{a a} P_{a}+B_{a b} P_{b}$, where $w_{a}$ is the mean yield per plant of component $a$ in the duoculture, $P_{a}$ and $P_{b}$ are the densities of $a$ and $b$, the two components 
of the mixture, and $A, B_{a a}$ and $B_{a b}$ are parameters to be estimated from the data. In 5 out of 6 cases he obtains good fits of the model to the data for a mixture of red clover and Italian ryegrass. His aim differs from ours in that his chief concern is with the effect of overall density on total yield, $Y=p w$, of the components taken separately and together in his mixtures. His experiments thus require variation of the total density of his mixture as well as of the relative densities of its components, and thus, as he himself notes, involve the simultaneous use of addition and substitution relationships. Our experiment is wholly of the substitution type and this is reflected in the analysis we have used. The reciprocal transformation, using $y^{-1}$ in place of $y$, is not effective in the analysis of these data. In particular its effect on the heterogeneity of the duplicate error variance is not to decrease but greatly to increase it, so precluding a joint analysis such as is made possible by the use of $\sqrt{y}$ (table 8 ).

This square root transformation was arrived at in an essentially empirical way, though with hindsight one might be tempted to relate its success to the fixed two dimensional pattern which broadly similar plants must display spatially and hence, one might suppose, competitively to one another. This is, however, no more than speculation. We must await the evidence from later years of the present experiment to see whether it continues to lead to fruitful analysis, and to the evidence from further experiments to see whether it is effective over a wider range of both situations and material, and whether any predictions to which it may lead can be verified.

\section{REFERENCES}

BREESE, E. L., AND HILL, J. 1973. Regression analysis of interactions between competing species. Heredity, 31, 181-200.

DURRANT, A. 1965. Analysis of reciprocal differences in diallel crosses. Heredity, 20, 573-607. HAYMAN, B. I. 1954. The theory and analysis of diallel crosses. Genetics, 39, 789-809.

HILL, J., AND SHIMAMOTO, Y. 1973. Methods of analysing competition with special reference to herbage plants. I. Establishment. J. Agric. Sci., Camb., 81, 77-89.

MATHER, K. AND CAligARI, P. D. S. 1981. Competitive interactions in Drosophila melanogaster. II. Measurement of competition. Heredity, 46, 239-254.

NORRINGTON-DAVIES, J. 1968. Diallel analysis of competition between grass species. $J$. Agric. Sci., Camb., 71, 223-231.

WILliAMS, E. J. 1962. The analysis of competition experiments. Aus. J. Biol. Sci., 15, 509-525.

WRIGHT, A. J. 1981. The analysis of yield-density-relationships in binary mixtures using inverse polynomials. J. Agric. Sci., Camb., 96, 561-567. 